\title{
Multiattribute Assessment of Consumables for TIG Welding of Aluminum Alloys
}

\author{
P. K. Baghel and D. S. Nagesh \\ Department of Mechanical Engineering, Delhi Technological University, Bawana Road, New Delhi 110042, India \\ Correspondence should be addressed to P. K. Baghel; pushpbaghel.pb@gmail.com
}

Received 23 August 2016; Revised 18 October 2016; Accepted 20 October 2016

Academic Editor: Jean Yves Hascoet

Copyright (C) 2016 P. K. Baghel and D. S. Nagesh. This is an open access article distributed under the Creative Commons Attribution License, which permits unrestricted use, distribution, and reproduction in any medium, provided the original work is properly cited.

\begin{abstract}
Consumable materials for welding processes such as filler alloy, electrode, and shielding gas have major implications in welding technology. Selecting the appropriate set of consumable materials for welding aluminum alloys from various available alternates gives rise to a significant decision making problem. This study proposes a strategic justification tool based on integrated analytical hierarchy process, technique for order preference by similarity to ideal solution (AHP-TOPSIS), to screen and select the best possible combination of filler alloy, electrode, and shielding gas for TIG welding. Based on qualitative analysis of available alternates, ER5356 filler alloys and $0.8 \%$ zirconiated electrode are selected as suitable consumable in combination with pure argon as shielding gas. The proposed result is experimentally validated using mechanical property testing.
\end{abstract}

\section{Introduction}

Dissimilar aluminum alloys combinations are widely used in aerospace and automobile applications such as inner body panel, heat shields, structural components, ladders, and space frames [1]. Several welding processes such as friction stir welding (FSW) and laser welding are gaining popularity for welding aluminum but TIG welding is still most widely used process for joining aluminum because of its heat control ability (narrow heat affected zone) and eco-friendly nature (no spatter and smoke). Although friction stir welding has several advantages like no voids and cracking, no distortion of workpiece, no need of filler material, no shielding gas required, clean and environment friendly process because there are no harmful effects like arc formation, radiation, release of toxic gas, and so forth, however as compared to TIG welding process some disadvantages of the friction stir welding process have been identified as well such that exit hole is left when the tool is withdrawn. This limitation is serious when pressure vessels and cargo oil tanks are manufactured. Heavy-duty clamping is required to hold the plates to combat large downward force. In addition to this it is less flexible that is difficult to weld when thickness varies.
The ideal weld joint should have tensile strength close to base metal and must be free from hot cracks and residual stress. Consumable materials, namely, filler alloy, electrode, and shielding gas, play a vital role in deciding the manufacturing quality and cost of weld joint [2].

When multiple choices are present, choosing the optimum material of desired properties from large number of available materials is a tedious task. It is essential to base the final decision using well-structured selection methodology in consideration with all possible relevant attributes or properties. Multiattribute decision making (MADM) models are generally used to provide an encompassing analysis of all involved multiple attributes.

In an unstructured decision problem in welding processes, such models have recently been used by many researchers. Khorshidi et al. [3] used TOPSIS for selecting the optimal refinement condition to achieve maximum tensile property in $\mathrm{Al}-15 \% \mathrm{Mg}_{2} \mathrm{Si}$ composite whereas Mirhedayatian et al. [4] employed TOPSIS approach and integrated fuzzy data envelopment analysis in welding process selection for repairing nodular cast iron engine block.

The selection of consumable materials is of prime importance to accomplish the joint of desired specifications; however there are not enough investigations in this direction. 
TABLE 1: List of attributes and alternates for filler alloy [1].

\begin{tabular}{|c|c|c|c|c|c|}
\hline Properties & ER5356 & ER5556 & ER5183 & ER5654 & ER5554 \\
\hline (1) Yield strength (MPa) & 240 & 158.579 & 275 & 220.63 & 124.10 \\
\hline (2) Tensile strength (MPa) & 268.89 & 317.15 & 296.47 & 227.52 & 186 \\
\hline (3) Elongation 2\% & 17 & 14 & 17 & 17 & 8 \\
\hline $\begin{array}{l}\text { (4) Brinell hardness (HB) } \\
\text { (@load } 500 \mathrm{Kg} \text { : thickness 10:ohm) }\end{array}$ & 105 & 65 & 99 & 83 & 39 \\
\hline (5) Cost $(\$)$ & 13.5 & 16 & 15.5 & 17.2 & 13 \\
\hline (6) Longitudinal shear strength (MPa) & 117.21 & 137.89 & 127.55 & 82.73 & 79.289 \\
\hline (7) Transverse shear strength (MPa) & 179.26 & 206.84 & 193.05 & 124.10 & 103.42 \\
\hline (8) Impact strength $(J)$ & 18.2 & 15.7 & 16 & 13 & 10 \\
\hline
\end{tabular}

TABLE 2: List of attributes and alternates for electrode [2].

\begin{tabular}{|c|c|c|c|c|c|}
\hline Properties & Pure tungsten & $2 \%$ thoriated & $2 \%$ ceriated & $1.5 \%$ lanthanated & $0.8 \%$ zirconiated \\
\hline $\begin{array}{l}\text { (1) Electrode oxide } \\
\text { work function }(\mathrm{eV})\end{array}$ & 0.01 & 2.6 & 3.2 & 2.5 & 0.3 \\
\hline (2) Density $\left(\mathrm{g} / \mathrm{cm}^{3}\right)$ & 19.25 & 11.72 & 6.65 & 5.7 & 6.49 \\
\hline $\begin{array}{l}\text { (3) Volume } \% \text { of } 2 \% \\
\text { weight of electrode }\end{array}$ & 6 & 3.8 & 5.2 & 5.7 & 6.9 \\
\hline (4) Melting point $\left({ }^{\circ} \mathrm{C}\right)$ & 3410 & 1750 & 795 & 826 & 1852 \\
\hline $\begin{array}{l}\text { (5) Electron negativity } \\
\text { (according to pauling) }\end{array}$ & 1.7 & 1.3 & 1.0 & 1.1 & 1.2 \\
\hline (6) Cost (\$) & 23.99 & 14.99 & 18.4 & 23.99 & 20.3 \\
\hline (7) Particle size (Nm) & 30 & 50 & 40 & 20 & 30 \\
\hline
\end{tabular}

Therefore there is a need for an extensive selection framework before undertaking the manufacturing process.

In present research, technique for order preference by similarity to ideal solution (TOPSIS) integrated with analytical hierarchy process (AHP) is employed to select an optimal combination of consumable materials for welding dissimilar aluminum alloys.

\section{Materials and Methodology}

Consumables in welding processes comprise filler alloy, electrode material, and shielding gas. The filler alloy determines the transverse and longitudinal strength of the weld joint. Therefore the filler material should have attributes like high tensile properties, impact toughness, and low cost. There are mainly five filler alloys that are used and listed in Table 1.

Table 2 presents the alternates and attributes of electrode used in pulse TIG welding of aluminum alloys. Tungsten electrode used in TIG welding is a consumable. It merely serves as the terminal for the electric arc which produces the heat needed to join the base metal being welded. The shape of the tungsten electrode tip is an important process variable in GTA welding. Tungsten electrode geometry has an effect on the arc shape (thereby affecting the weld bead size and shape), the weld penetration, and point longevity of the electrode. In addition to the arc shape, different tungsten materials pose different characteristics which influence arc start ability, electrode life, and contamination resistance.

Selection of right shielding gas composition significantly affects metallurgical structure, properties, soundness, and heat treated response of weld. The desired characteristics with suitable alternates are listed in Table 3.

TOPSIS method is employed to evaluate and find the best suitable alternative in the present work. It was first proposed in 1981 [5].

The methodology involves the evaluation of Euclidean distance from the positive and the negative ideal solution for the given alternate. The best possible alternative will be closest to the positive ideal solution and far away from negative ideal solution.

TOPSIS is a suitable choice for material selection as it is a relatively more systematic process. It provides both qualitative and quantitative analysis of the available data. The TOPSIS method involves a tool for evaluation of weights of each attribute/criterion. In this study, this task is performed using AHP method. The relative weights hence generated are used in TOPSIS process to find the final priority ranking of available alternatives.

It was developed by Satty [6] to handle complex problems based on multiple criteria. The flexibility and intuitiveness of AHP method provide edge over other methods. It facilitates group decision making by finding the geometric mean of the individual pairwise comparisons.

Figure 1 depicts (AHP-TOPSIS) MADM methodology for welding process consumables selection.

The AHP Method. To determine the relative importance of different attributes with respect to the objective the following steps are followed. 
TABLE 3: List of attributes and alternates for shielding gas $[7,8]$.

\begin{tabular}{|c|c|c|c|c|c|}
\hline Properties & Pure argon & Pure helium & $\begin{array}{c}25 \% \text { argon }+75 \% \\
\text { helium }\end{array}$ & $75 \%$ argon $+25 \%$ helium & $50 \%$ argon $+50 \%$ helium \\
\hline $\begin{array}{l}\text { (1) Thermal conductivity } \\
\mathrm{W} / \mathrm{mK} \text { at }\left(1.013 \text { bar at } 0^{\circ} \mathrm{C}\right)\end{array}$ & 0.016 & 0.1513 & 0.1174 & 0.0498 & 0.0836 \\
\hline $\begin{array}{l}\text { (2) Gas density (lb/wft) at } 0^{\circ} \mathrm{C} \text {, } \\
1 \mathrm{~atm}\end{array}$ & 0.1114 & 0.0111 & 0.0361 & 0.0863 & 0.0612 \\
\hline $\begin{array}{l}\text { (3) Specific gravity }\left(\mathrm{g} / \mathrm{cm}^{3}\right) \text { air }= \\
1\end{array}$ & 1.38 & 0.1368 & 0.4476 & 1.0692 & 0.7584 \\
\hline (4) Ionization potential $(\mathrm{eV})$ & 15.7 & 24.5 & 22.3 & 17.9 & 20.1 \\
\hline (5) Cost (per $100 \mathrm{~g})(\$)$ & 0.5 & 5.2 & 4.025 & 1.675 & 4.15 \\
\hline $\begin{array}{l}\text { (6) Specific heat capacity at } \\
\mathrm{kJ} / \mathrm{Kg} \cdot \mathrm{K} C_{p}\left(1.013 \text { bar and } 25^{\circ} \mathrm{C}\right)\end{array}$ & 0.520 & 5.19 & 4.0225 & 1.6875 & 2.855 \\
\hline
\end{tabular}

TABLE 4: Nine-point intensity of importance scale.

\begin{tabular}{lc}
\hline Relative importance $\left(a_{i j}\right)$ & Description $(i$ over $j)$ \\
\hline 1 & Equal importance \\
3 & Moderate importance \\
5 & Strong importance \\
7 & Very strong importance \\
9 & Absolute importance \\
$2,4,6,8$ & Intermediate values \\
\hline
\end{tabular}

The multiple pairwise comparisons are based on a standardized comparison scale of nine levels (Table 4).

Let $C=\left\{C_{j} \mid j=1,2, \ldots, n\right\}$ be the set of criteria.

The result of the pairwise comparison on $n$ criteria can be summarized in an $(n \times n)$ evaluation matrix $A$. Every element $a_{i j}(i, j=1,2, \ldots, n)$ denotes the relative importance of factor $i$ with respect to factor $j$. A criterion compared with itself is always assigned the value 1 so the main diagonal entries of the pairwise comparison matrix are all 1.

Square matrix $A$ containing every element $a_{i j}$ is shown in

$$
A=\left(\begin{array}{cccc}
1 & a_{12} & \cdots & a_{1 m} \\
a_{21} & 1 & \cdots & a_{2 m} \\
\vdots & \cdots & \vdots & \vdots \\
a_{m 1} & a_{m 2} & \cdots & 1
\end{array}\right), \quad a_{i j}=\frac{1}{a_{j i}}, a_{j i \neq 0} .
$$

(i) The relative normalized weight $\left(W_{i}\right)$ of each factor is evaluated by finding the geometric mean of $i$ th row and normalizing the geometric means of rows in the comparison matrix

$$
\begin{aligned}
\mathrm{GM}_{i} & =\left\{a_{i 1} \times a_{i 2} \times a_{i 3} \times \cdots \times a_{i j}\right\}^{1 / n}, \\
W_{i} & =\frac{\mathrm{GM}_{i}}{\sum_{j=1}^{j=n} \mathrm{GM}_{i}} .
\end{aligned}
$$

Matrix $X$ is obtained to denote an $n$-dimensional column vector. The sum of the weighted values is computed for the importance degrees of alternatives; then $X=A * W$, where

$$
\begin{aligned}
& W=\left[W_{1}, W_{2}, W_{3}, \ldots, W_{n}\right]^{T}, \\
& X=A * W=\left[\begin{array}{cccc}
1 & a_{12} & \cdots & a_{1 n} \\
a_{21} & 1 & \cdots & a_{2 n} \\
\vdots & \vdots & \cdots & \vdots \\
a_{n 1} & a_{n 2} & \cdots & 1
\end{array}\right]\left[\begin{array}{c}
W_{1} \\
W_{2} \\
\vdots \\
W_{n}
\end{array}\right]=\left[\begin{array}{c}
C_{1} \\
C_{2} \\
\vdots \\
C_{n}
\end{array}\right] .
\end{aligned}
$$

(ii) The consistency values (CV) are calculated for the cluster of alternatives represented by the vector

$$
\mathrm{CV}_{i}=\frac{C_{i}}{W_{i}} .
$$

(iii) The largest eigenvalue $\lambda_{\max }$ is obtained which is the mean of the consistency values.

(iv) The consistency index (CI) is calculated by

$$
\mathrm{CI}=\frac{\lambda_{\max }-n}{n-1}
$$

The AHP output quality is strictly related to the consistency of the pairwise comparison judgements.

(vi) The random index (RI) is obtained for the number of factors being used in decision making (Table 5).

(vii) The final consistency ratio (CR) is calculated as the ratio of the $\mathrm{CI}$ and $\mathrm{CR}$

$$
\mathrm{CR}=\frac{\mathrm{CI}}{\mathrm{RI}}
$$

The acceptable upper limit for CR is 0.1. The evaluation process has to be repeated to improve the consistency, if the final consistency ratio exceeds this value. This consistency check is essential to establish the validity of the pairwise comparison matrix evaluation.

TOPSIS method consists of the following steps. 


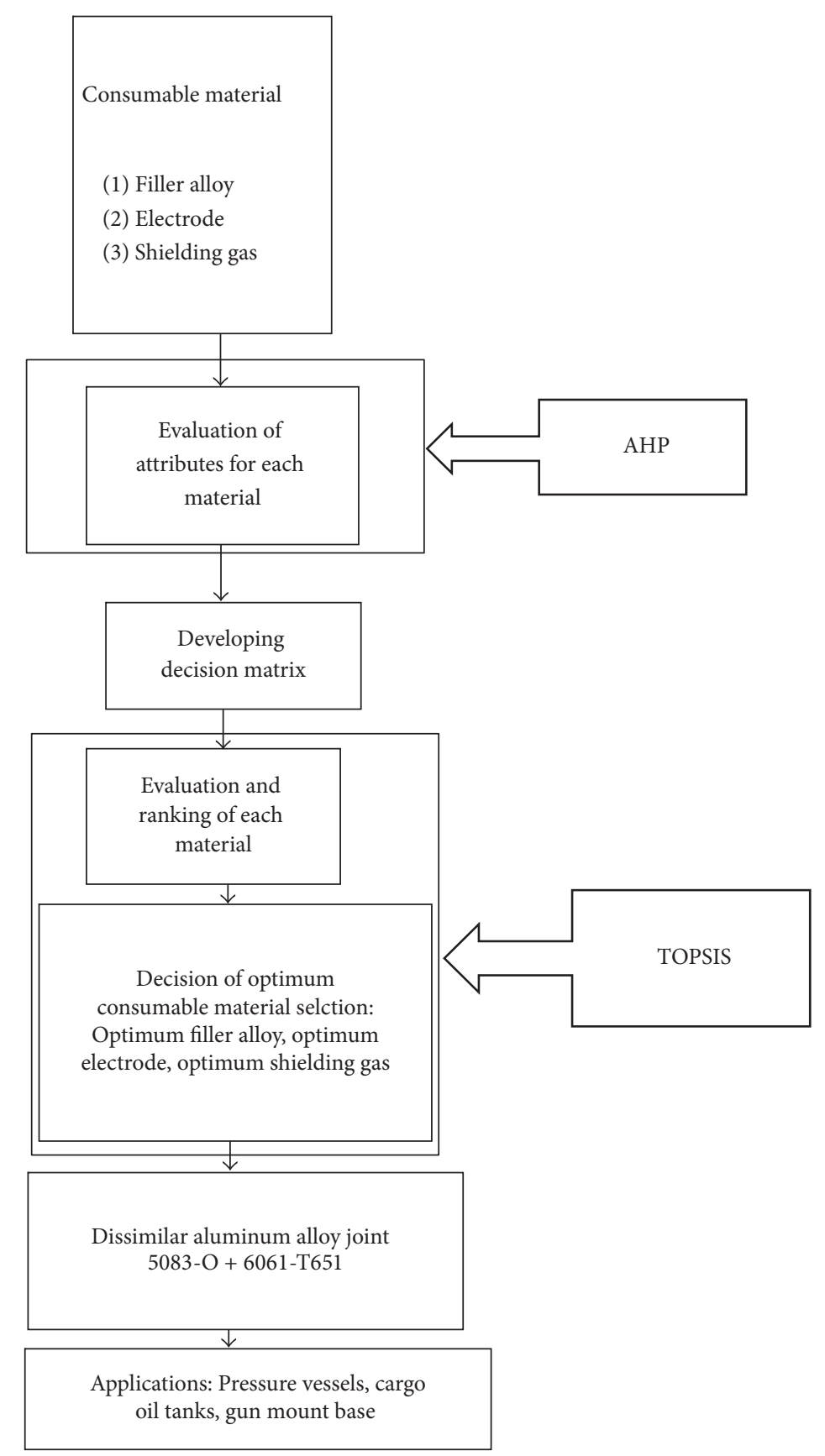

FIGURE 1: Flow chart depicting integrated AHP-TOPSIS methodology for consumable materials selection.

TABLe 5: Random index (RI) values.

\begin{tabular}{lccc}
\hline Criteria & RI & Criteria & RI \\
\hline 3 & 0.52 & 7 & 1.35 \\
4 & 0.89 & 8 & 1.40 \\
5 & 1.11 & 9 & 1.45 \\
6 & 1.25 & 10 & 1.49 \\
\hline
\end{tabular}

Step 1 (construction of the normalized decision matrix). For the Euclidean length of a vector, the element $r_{i j}$ of the normalized decision matrix $R$ is evaluated using the following transformation:

$$
r_{i j}=\frac{X_{i j}}{\sqrt{\sum_{i=1}^{m}\left(X_{i j}\right)^{2}}}, \quad j=1,2, \ldots, n ; i=1,2, \ldots, m .
$$

Here, $r_{i j}$ is the normalized preference measure of the $i$ th alternative. " $m$ " is the number of alternatives, and " $n$ " is the number of criteria. 
Step 2 (construction of the weighted normalized decision matrix). Multiply the columns of the normalized decision matrix with the set of weights obtained by AHP.

$W=\left(w_{1}, w_{2}, w_{3}, \ldots, w_{n}\right)$ to obtain weighted normalized decision matrix:

$V=R W$

$$
=\left(\begin{array}{cccc}
w_{1} \cdot r_{11} & w_{2} \cdot r_{12} & \cdots & w_{n} \cdot r_{1 n} \\
w_{1} \cdot r_{21} & w_{2} \cdot r_{22} & \cdots & w_{n} \cdot r_{2 n} \\
\vdots & \vdots & & \vdots \\
w_{1} \cdot r_{m 1} & w_{2} \cdot r_{m 2} & \cdots & w_{n} \cdot r_{m n}
\end{array}\right) .
$$

Step 3 (determination of the ideal and negative ideal solutions). The ideal solution and negative ideal solution value sets are determined, respectively, as follows:

$$
\begin{aligned}
& \left\{V_{1}^{+}, V_{2}^{+}, \ldots, V_{n}^{+}\right\} \\
& \quad=\left\{\left(\max _{i} V_{i j} \mid J \in K\right),\left(\min _{i} V_{i j} \mid J \in K^{\prime}\right) \mid i\right. \\
& \quad=1,2, \ldots, m\}, \\
& \left\{V_{1}^{-}, V_{2}^{-}, \ldots, V_{n}^{-}\right\} \\
& \quad=\left\{\left(\min _{i} V_{i j} \mid J \in K\right),\left(\max _{i} V_{i j} \mid J \in K^{\prime}\right) \mid i\right. \\
& \quad=1,2, \ldots, m\},
\end{aligned}
$$

where

$$
\begin{aligned}
K= & \{j=1,2,3, \ldots, n, \\
& j \text { is associated with benefit criteria }\}, \\
K^{\prime} & =\{j=1,2,3, \ldots, n, \\
& j \text { is associated with cost criteria }\} .
\end{aligned}
$$

Step 4 (measurement of separation distances from ideal and negative ideal solutions). Euclidean distances for each alternative are, respectively, calculated as

$$
\begin{aligned}
& S_{i}^{+}=\left\{\sum_{j=1}^{n}\left(V_{i j}-V_{j}^{+}\right)^{2}\right\}^{1 / 2} ; i=1,2, \ldots, m, \\
& S_{i}^{-}=\left\{\sum_{j=1}^{n}\left(V_{i j}-V_{j}^{-}\right)^{2}\right\}^{1 / 2} ; i=1,2, \ldots, m .
\end{aligned}
$$

Step 5 (calculation of the relative closeness to the ideal solution). The relative closeness to the ideal solution can be defined as

$$
C_{i}=\frac{S_{i}^{-}}{S_{i}^{+}+S_{i}^{-}} ; \quad i=1,2, \ldots, m ; 0 \leq C_{i} \leq 1 .
$$

The higher the closeness means the better the rank.

Step 6 (ranking of the preference order). The preference order is ranked on the basis of the order of $C_{i}$. Hence, the optimum alternative is the one which is nearer to the ideal solution and farther to the negative ideal solution.

\section{Result and Discussion}

3.1. Computational Results. The normalized decision matrix for filler alloy, electrode, and shielding gas is calculated using (7) as shown in matrices (13), (14), and (15), respectively, 


$$
\begin{gathered}
{\left[\begin{array}{llllllll}
0.0021 & 0.7691 & 0.4781 & 0.7735 & 0.5927 & 0.5203 & 0.3780 & 0.5401 \\
0.5383 & 0.4682 & 0.3028 & 0.3970 & 0.4533 & 0.3251 & 0.6300 & 0.4659 \\
0.6625 & 0.2657 & 0.4143 & 0.1803 & 0.3487 & 0.3990 & 0.5040 & 0.4748 \\
0.5176 & 0.2277 & 0.4542 & 0.1874 & 0.3835 & 0.5203 & 0.2520 & 0.3858 \\
0.0621 & 0.2593 & 0.5498 & 0.4201 & 0.4184 & 0.4403 & 0.3780 & 0.2967
\end{array}\right]} \\
{\left[\begin{array}{lllllll}
0.0743 & 0.7042 & 0.7041 & 0.3452 & 0.0705 & 0.0627 \\
0.7024 & 0.0702 & 0.0698 & 0.5387 & 0.7038 & 0.6525 \\
0.5450 & 0.2282 & 0.2284 & 0.4903 & 0.5455 & 0.5050 \\
0.2312 & 0.5455 & 0.5455 & 0.3936 & 0.2288 & 0.2102 \\
0.3881 & 0.3869 & 0.3869 & 0.4420 & 0.3871 & 0.5207
\end{array}\right]}
\end{gathered}
$$

These weights of all attributes of respective consumables are evaluated using AHP method and the results are presented in Table 6.
A weighted normalized decision matrix for filler alloy, electrode, and shielding gas is presented in matrices (16)

$$
\begin{gathered}
{\left[\begin{array}{llllllll}
0.0174 & 0.0100 & 0.0241 & 0.0608 & 0.1323 & 0.0739 & 0.1112 & 0.0427 \\
0.0103 & 0.0132 & 0.0199 & 0.0376 & 0.1568 & 0.0869 & 0.1283 & 0.0368 \\
0.0192 & 0.0115 & 0.0241 & 0.0573 & 0.1519 & 0.0804 & 0.1197 & 0.0375 \\
0.0148 & 0.0092 & 0.0241 & 0.0481 & 0.1686 & 0.0522 & 0.0770 & 0.0305 \\
0.0081 & 0.0078 & 0.0113 & 0.0226 & 0.1274 & 0.0500 & 0.0641 & 0.0234
\end{array}\right],} \\
{\left[\begin{array}{lllllllll}
0.0001 & 0.0344 & 0.0755 & 0.0797 & 0.1417 & 0.1842 & 0.0255 & 0.0427 \\
0.0167 & 0.0209 & 0.0478 & 0.0409 & 0.1083 & 0.1151 & 0.0425 & 0.0368 \\
0.0206 & 0.0119 & 0.0655 & 0.0186 & 0.0833 & 0.1413 & 0.0340 & 0.0375 \\
0.0161 & 0.0102 & 0.0718 & 0.0193 & 0.0917 & 0.1842 & 0.0170 & 0.0305 \\
0.0019 & 0.0116 & 0.0869 & 0.0433 & 0.1000 & 0.1558 & 0.0255 & 0.0234
\end{array}\right],} \\
{\left[\begin{array}{llllllll}
0.0032 & 0.0708 & 0.1123 & 0.0221 & 0.0177 & 0.0240 \\
0.0301 & 0.0071 & 0.0111 & 0.0345 & 0.1762 & 0.2495 \\
0.0233 & 0.0230 & 0.0364 & 0.0314 & 0.1366 & 0.1931 \\
0.0099 & 0.0549 & 0.0870 & 0.0252 & 0.0573 & 0.0804 \\
0.0166 & 0.0389 & 0.0617 & 0.0283 & 0.0969 & 0.1991
\end{array}\right]}
\end{gathered}
$$

3.2. Ranking Results. The relative closeness to the ideal solution hence can be found using (12). The ranks are assigned based on their " $C$ " values and are given in Table 7 . The larger the value of closeness the better the rank.

It can be concluded from Table 7, filler alloy, ER5356 has the highest ranking followed by ER5183 while ER5654 is the least ranked material. In arc electrode selection problem the optimum arc electrode is $0.8 \%$ zirconiated electrode which is the best alternate as it has slightly higher " $C$ " value than $2 \%$ thoriated electrode. Shielding gas analysis results indicate pure argon as the optimum consumable component closely followed by Ar-He gas blend as second best alternative. The block diagram for material selection application has been shown in Figure 2.

3.3. Welding Experimentation. The butt welding of aluminum alloy of 5083-O and 6061-T651 using pulse TIG welding (Triton $220 \mathrm{AC} / \mathrm{DC}$ ) is performed to establish the applicability and validity of the selection model.

The chemical composition of filler alloys used has been depicted in Table 8. 
TABLE 6: Weights of the attributes from AHP method.

\begin{tabular}{lccc}
\hline Attributes & Filler alloy weights & Electrode weights & Shielding gas weights \\
\hline$A_{1}$ & 0.0326 & 0.0311 & 0.0428 \\
$A_{2}$ & 0.0235 & 0.0447 & 0.1006 \\
$A_{3}$ & 0.0476 & 0.1586 & 0.1595 \\
$A_{4}$ & 0.1059 & 0.1036 & 0.0640 \\
$A_{5}$ & 0.3313 & 0.2399 & 0.2504 \\
$A_{6}$ & 0.1572 & 0.3542 & 0.3824 \\
$A_{7}$ & 0.2306 & 0.0675 & \\
$A_{8}$ & 0.0709 & & \\
\hline
\end{tabular}

TABLE 7: TOPSIS analysis result.

\begin{tabular}{|c|c|c|c|c|c|c|c|c|}
\hline \multicolumn{3}{|c|}{ Filler alloy } & \multicolumn{3}{|c|}{ Electrode } & \multicolumn{3}{|c|}{ Shielding gas } \\
\hline Alternates & $C_{i}$ & Rank & Alternates & $C_{i}$ & Rank & Alternates & $C_{i}$ & Rank \\
\hline $\operatorname{ER} 5356\left(C_{1}\right)$ & 0.8358 & 1 & Pure tungsten $\left(C_{1}\right)$ & 0.4084 & 4 & Pure argon $\left(C_{1}\right)$ & 0.7149 & 1 \\
\hline $\operatorname{ER} 5556\left(C_{2}\right)$ & 0.6184 & 3 & $2 \%$ thoriated $\left(C_{2}\right)$ & 0.5789 & 2 & Pure helium $\left(C_{2}\right)$ & 0.2850 & 4 \\
\hline $\operatorname{ER} 5183\left(C_{3}\right)$ & 0.7205 & 2 & $2 \%$ ceriated $\left(C_{3}\right)$ & 0.4745 & 3 & $25 \%$ argon $+75 \%$ helium $\left(C_{3}\right)$ & 0.3280 & 3 \\
\hline $\operatorname{ER5654}\left(C_{4}\right)$ & 0.3142 & 5 & $1.5 \%$ lanthanated $\left(C_{4}\right)$ & 0.2835 & 5 & $75 \%$ argon $+25 \%$ helium $\left(C_{4}\right)$ & 0.6719 & 2 \\
\hline $\operatorname{ER5554}\left(C_{5}\right)$ & 0.3516 & 4 & $0.8 \%$ zirconiated $\left(C_{5}\right)$ & 0.5869 & 1 & $50 \%$ argon $+50 \%$ helium $\left(C_{5}\right)$ & 0.2363 & 5 \\
\hline
\end{tabular}

TABLE 8: Chemical composition of filler alloys used.

\begin{tabular}{lccccccccc}
\hline Composition & $\mathrm{Si}$ & $\mathrm{Mg}$ & $\mathrm{Fe}$ & $\mathrm{Cu}$ & $\mathrm{Mn}$ & $\mathrm{Cr}$ & $\mathrm{Zn}$ & $\mathrm{Ti}$ & $\mathrm{Al}$ \\
\hline ER5356 & 0.23 & 5.0 & 0.40 & 0.05 & 0.12 & 0.9 & 0.10 & 0.13 & Balance \\
ER5556 & 0.25 & 5.1 & 0.40 & 0.10 & 0.75 & 0.13 & 0.25 & 0.13 & Balance \\
ER5183 & 0.40 & 4.8 & 0.40 & 0.10 & 0.75 & 0.15 & 0.25 & 0.15 & Balance \\
ER5654 & 0.22 & 3.5 & 0.23 & 0.05 & 0.01 & 0.25 & 0.20 & 0.10 & Balance \\
ER5554 & 0.25 & 2.7 & 0.40 & 0.10 & 0.75 & 0.13 & 0.25 & 0.13 & Balance \\
\hline
\end{tabular}

Experimental validation has been conducted using highest ranking materials, namely, ER5356 as filler alloy, 0.8\% zirconiated electrode, and pure argon shielding gas as shown in Figure 3.

3.3.1. Radiography Examination. Welding was examined using radiography to check lack of penetration as shown in Figure 4. No visual defects are observed in radiography film indicating proper fusion in weld joint leading to successful welding. $10 \times 12 \mathrm{~cm}$ is the scale bar used.

3.3.2. Microstructure Characterizations. Microstructural characterization is important since various characteristics of phase particles especially mechanical properties, corrosion resistance, are dependent on form of $\mathrm{Mg}_{2} \mathrm{Si}$ in which it exists in a particular material.

Microstructural characterization uses optical microscope and SEM (scanning electron microscope) images $(3700 \mathrm{~N}$ Hitachi) to check grain refining and formation of brittle phase shown in Figure 5.

Microstructure shows three different regions, that is, base metal, heat affected zone, and fusion zone on either side of weld. Figure 6 shows fusion zone (FZ) region, in which fine equiaxed grains of aluminum solid solution containing soluble phase consisting of $\mathrm{Mg}_{2} \mathrm{Si}$ particles show proper grain refinement. Hence improved weld quality is accomplished.

\section{Conclusion}

Selection of welding process consumables is important tasks of decision making in engineering design. There is a requirement to study the correlation between available material alternates and their attributes to produce a robust welding of aluminum alloys at the lowest overall cost. AHP-TOPSIS based MADM model makes it possible to provide both qualitative and quantitative study of intangible factors in welding process.

The relevance of such decision support tool lies in enabling welding/design engineers to improvise the process management with minimum available data.

In future research the approach can be used for selection of dissimilar metal alloys for common extrusion applications.

\section{Competing Interests}

The authors declare that they have no competing interests. 


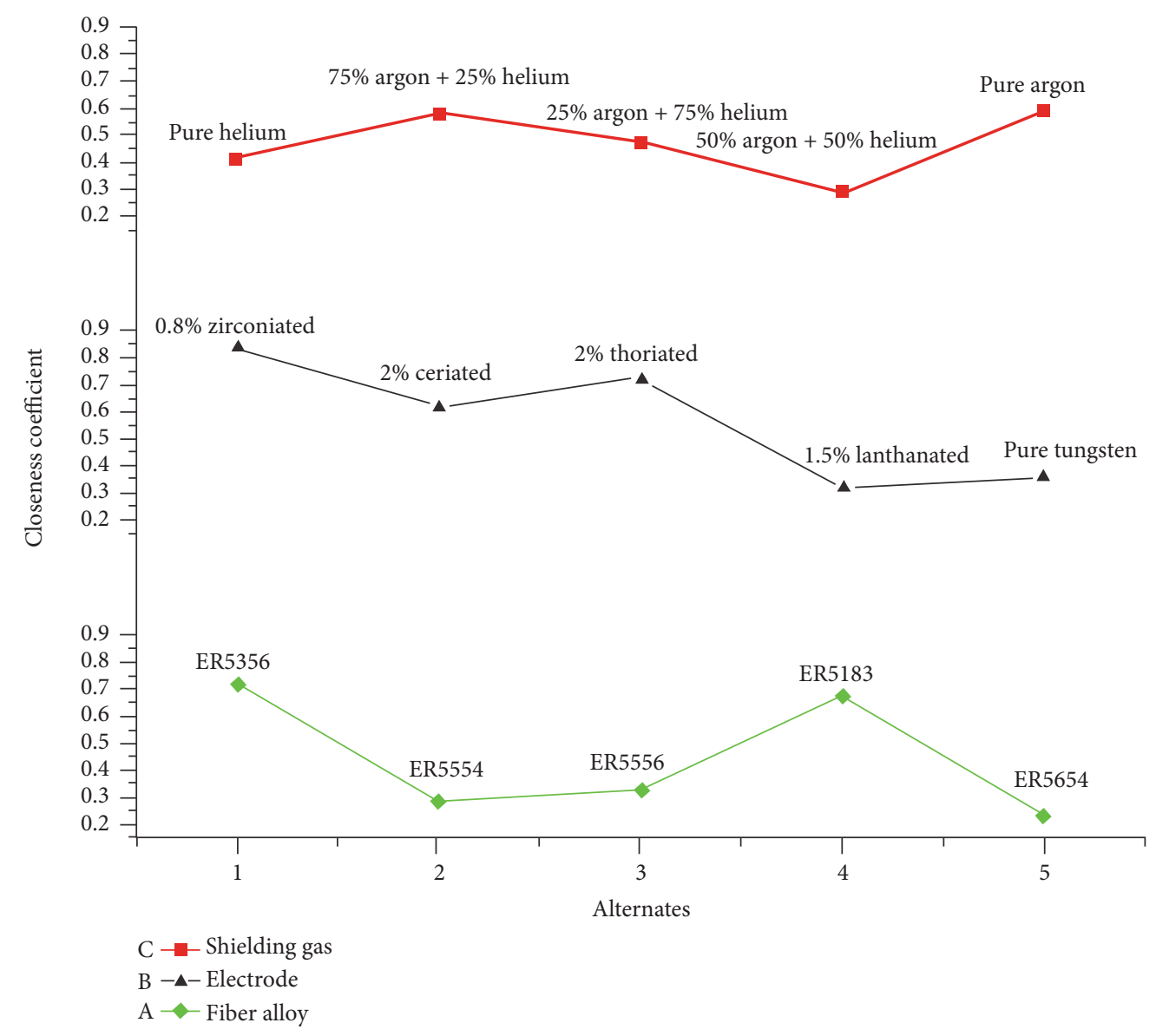

FIGURE 2: Block diagram for material selection application.

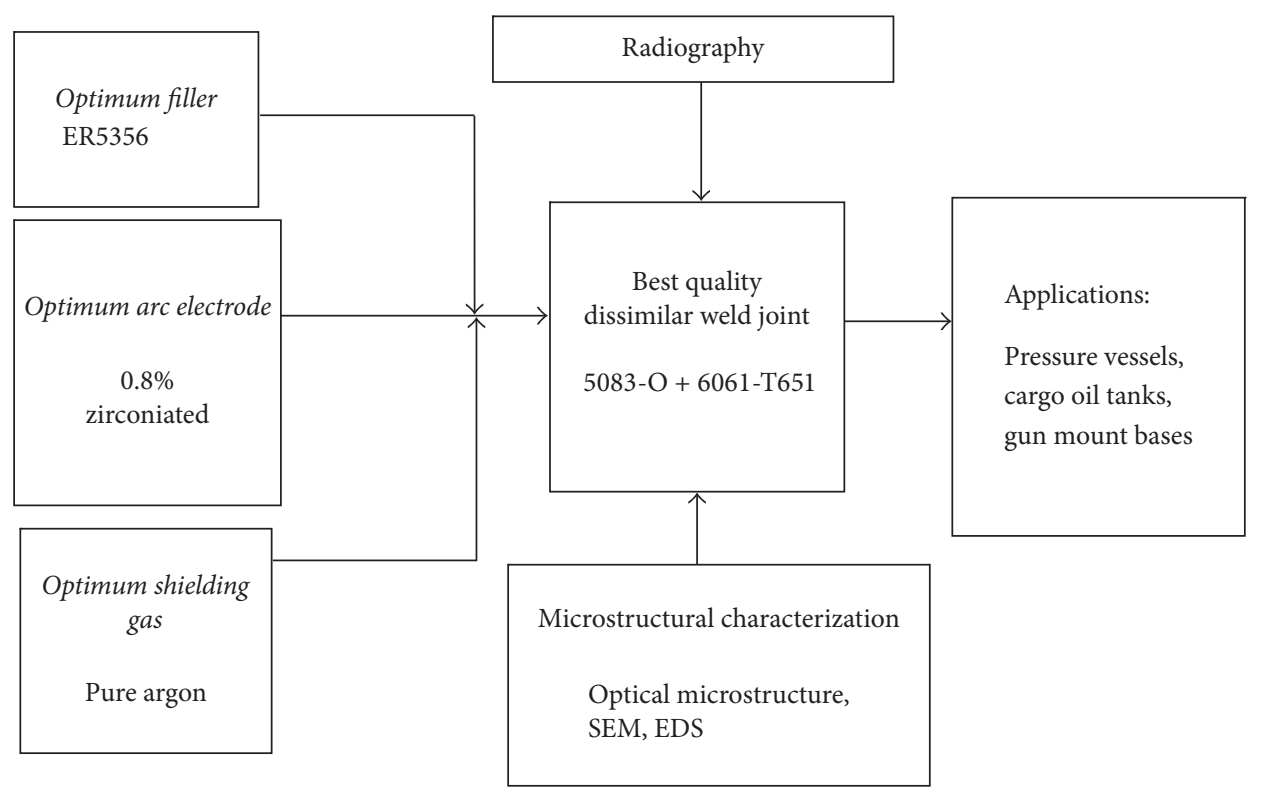

FIgURE 3: Flow diagram depicting applications of 5083-O and 6061-T651. 


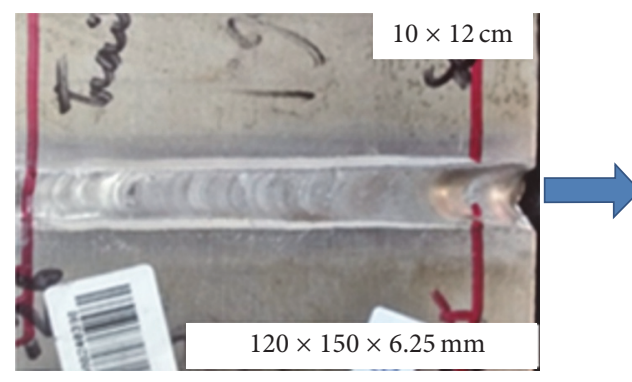

(a)

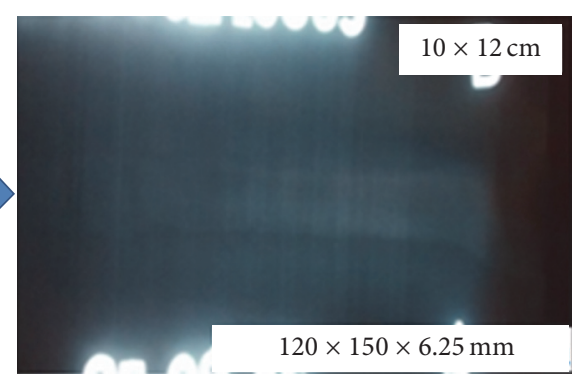

(b)

Figure 4: (a) Weld joint 5083-O + 6061 T-651. (b) Radiography.
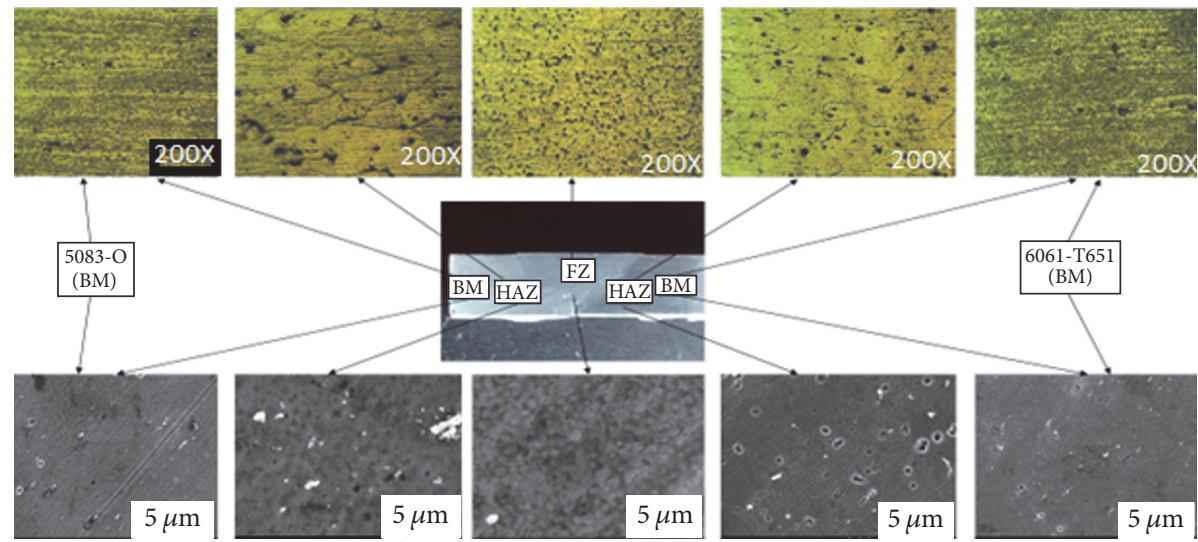

Figure 5: Microstructure (200x) and SEM $(5 \mu \mathrm{m})$ images of base metal, heat affected zone, and fusion zone at both sides.

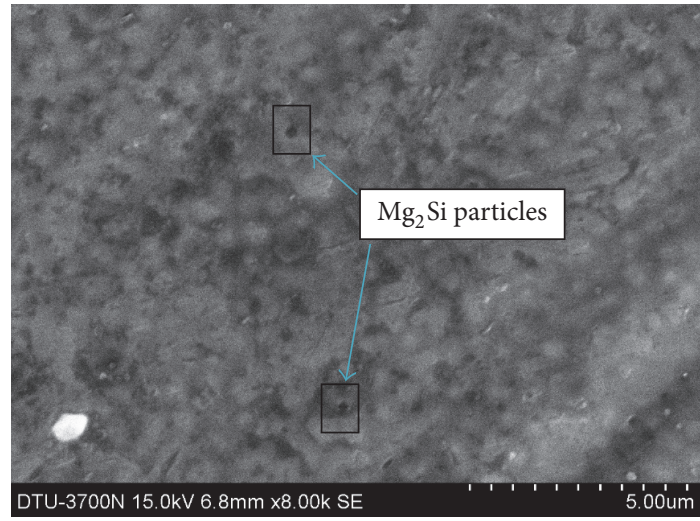

FIGURE 6: SEM image of $\mathrm{Mg}_{2} \mathrm{Si}$ particle.

\section{References}

[1] K. Mutombo, Corrosion of fatigue behaviour of 5083-H111 and 6061-T651 Aluminium alloy welds [Ph.D. thesis], University of Pretoria, South Africa, 2011.

[2] R. Scott Funderburk, "Key concepts in welding engineeringpost weld heat treatment," Welding Innovation, vol. 15, no. 2, 1998.

[3] R. Khorshidi, A. Hassani, A. H. Rauof, and M. Emamy, "Selection of an optimal refinement condition to achieve maximum tensile properties of $\mathrm{Al}-15 \% \mathrm{Mg}_{2} \mathrm{Si}$ composite based on TOPSIS method," Materials \& Design, vol. 46, pp. 442-450, 2013.
[4] S. M. Mirhedayatian, S. E. Vahdat, M. J. Jelodar, and R. F. Saen, "Welding process selection for repairing nodular cast iron engine block by integrated fuzzy data envelopment analysis and TOPSIS approaches," Materials and Design, vol. 43, pp. 272-282, 2013.

[5] C. Hwang and K. Yoon, Multiple Attribute Decision Making Methods and Application Survey, Springer, Berlin, Germany, 1981.

[6] T. L. Satty, "Decision making with the analytic hierarchy process," International Journal of Services Sciences, vol. 1, pp. 8398, 2008.

[7] H.-Y. Huang, "Effects of shielding gas composition and activating flux on GTAW weldments," Materials and Design, vol. 30, no. 7, pp. 2404-2409, 2009.

[8] H.-Y. Huang, "Argon-hydrogen shielding gas mixtures for activating flux-assisted gas tungsten arc welding," Metallurgical and Materials Transactions A: Physical Metallurgy and Materials Science, vol. 41, no. 11, pp. 2829-2835, 2010. 


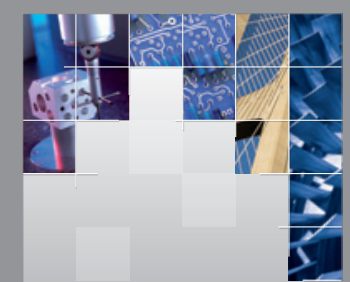

\section{Enfincering}
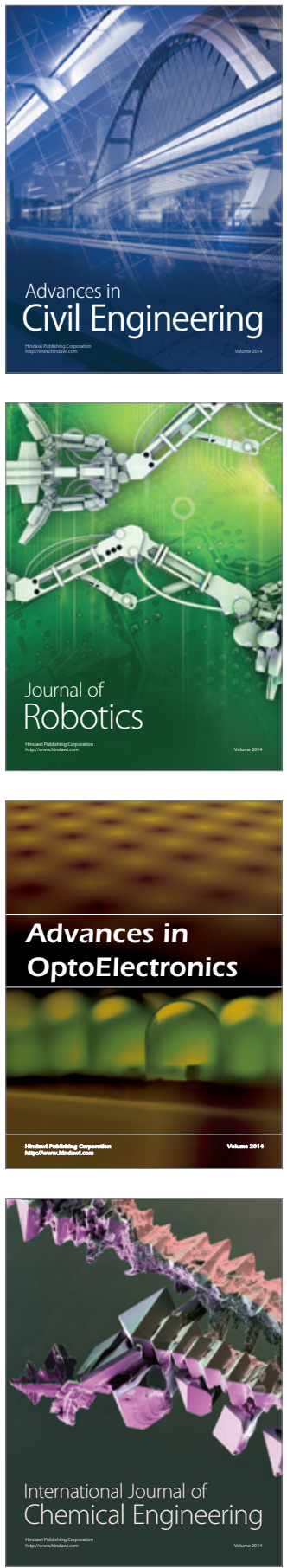

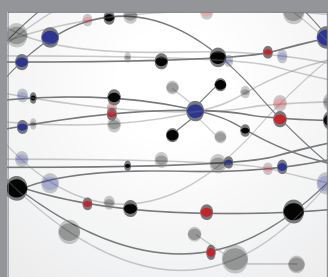

The Scientific World Journal

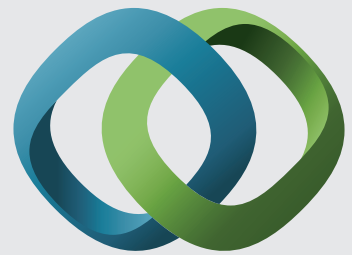

\section{Hindawi}

Submit your manuscripts at

http://www.hindawi.com
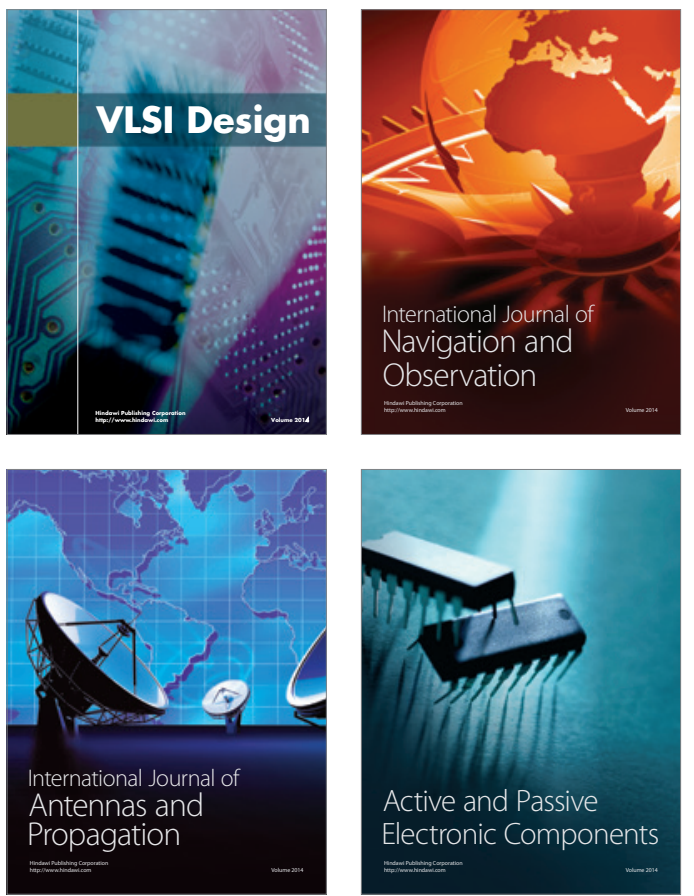
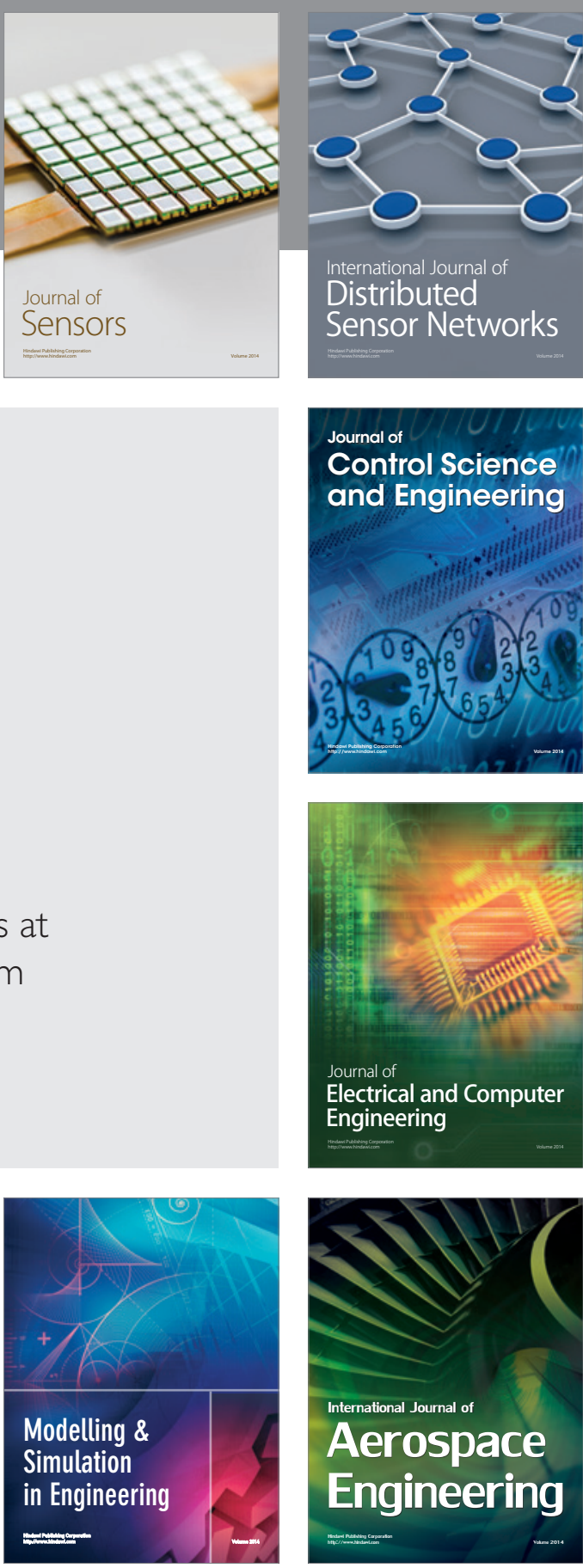

International Journal of

Distributed

Sensor Networks

Journal of

Control Science

and Engineering
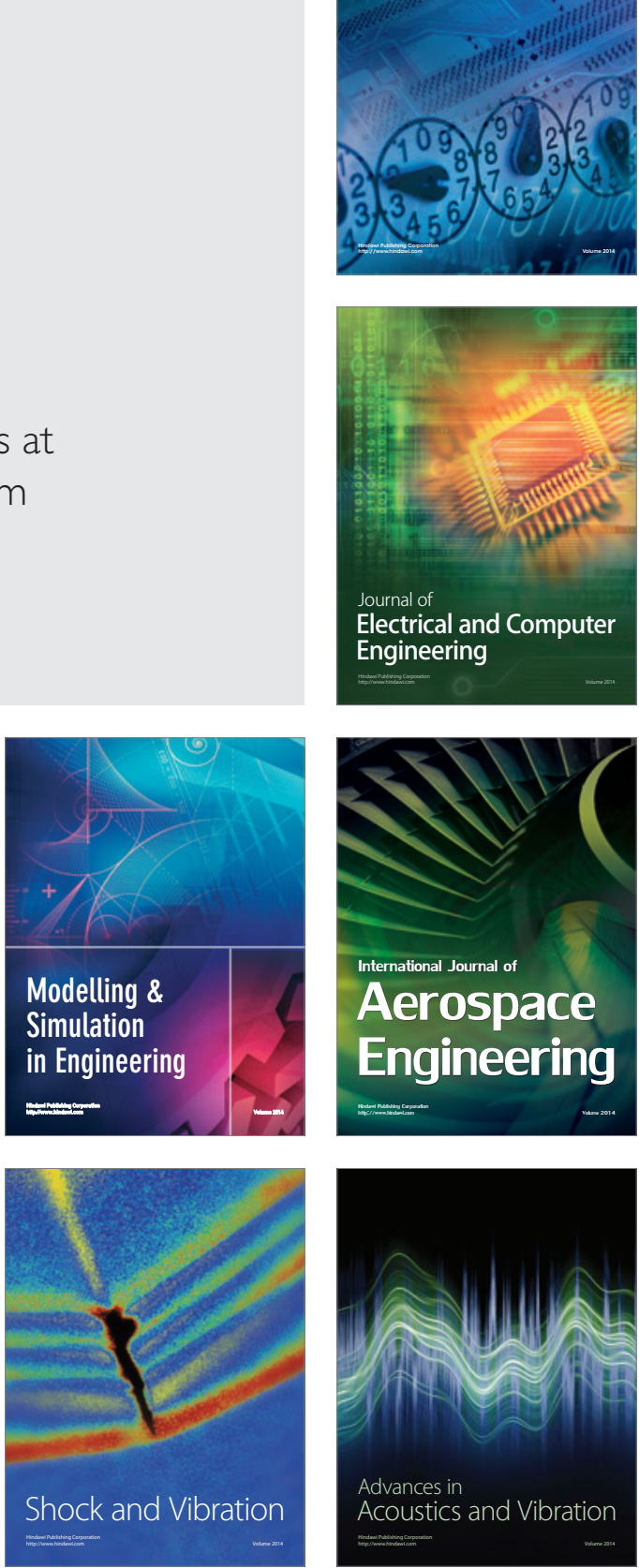